\author{
Y. Yulianto*, Z. Su'ud \\ Department of Physics, Bandung Institute of Technology, Bandung, Indonesia \\ *Corresponding author: yacyulianto@gmail.com

\section{NUCLEAR BINDING ENERGY AND DENSITY DISTRIBUTION OF Pb ISOTOPES IN A SKYRME - HARTREE - FOCK METHOD}

In this study, nuclear ground-state properties of spherical nuclei, such as the total energy, nucleon local density, and nucleon local potential of $\mathrm{Pb}$ isotopes (especially ${ }^{204-214} \mathrm{~Pb}$ ) are investigated by using Hartree - Fock method. The calculations have been performed by using Skyrme set parameters, especially SLy4, SkM*, Z ${ }_{\sigma}$, and SIII set parameters. The calculation results have been compared to the related experiment results and the calculation results of the other researchers. All parameters used in this study are in good agreement with the results of the related experiments and the other researchers. In $\mathrm{Pb}$ nucleus, it is also obtained from this study that the total energy, mass radius, neutron radius, neutron skin thickness, neutron density, neutron density width, proton potential depth, and proton potential width increase accordingly with the increase of neutron number. In other hand, proton density and neutron potential decrease accordingly with the increase of neutron number. The increase of neutron number has minimum effect to the widths of proton density and neutron potential.

Keywords: Hartree - Fock, local density, nuclear binding energy, Pb isotopes, Skyrme interaction.

\section{Introduction}

It is commonly known that lead $(\mathrm{Pb})$ has four stable isotopes, i.e. ${ }^{204} \mathrm{~Pb},{ }^{206} \mathrm{~Pb},{ }^{207} \mathrm{~Pb}$, and ${ }^{208} \mathrm{~Pb}$. ${ }^{204} \mathrm{~Pb}$ is entirely a primordial nuclide and is not a radiogenic nuclide. The next three isotopes, ${ }^{206} \mathrm{~Pb}$, ${ }^{207} \mathrm{~Pb}$, and ${ }^{208} \mathrm{~Pb}$, represent the ends of three natural decay chains: the uranium series (or radium series), the actinium series, and the thorium series, respectively. In burn-up process, ${ }^{212} \mathrm{~Pb}$ and ${ }^{208} \mathrm{~Pb}$ are the products of ${ }^{232} \mathrm{Th}$ series. The ${ }^{214} \mathrm{~Pb},{ }^{210} \mathrm{~Pb}$, and ${ }^{206} \mathrm{~Pb}$ are the products of ${ }^{238} \mathrm{U}$ series.

${ }^{208} \mathrm{~Pb}$ has an unusually low neutron capture crosssection (even lower than that of deuterium in the thermal spectrum) that makes it interesting to be applied in lead-cooled fast reactors [1]. The unique features of ${ }^{208} \mathrm{~Pb}$ lead to the economy of neutrons, hardening the neutron spectra, and other profitable factors [2]. It implies that $\mathrm{Pb}$ isotopes become very interesting to be investigated further, especially its ground-state properties.

The far-from-stability nuclei have attracted many scientists in recent years, especially observation about the new nuclear structure phenomena, such as the neutron halo and the neutron skin in light nuclei. Theoretically, microscopic mean-field approaches have been very successful in describing ground-state properties of nuclei to explain the experiment results. One of the methods that can be used is Skyrme - Hartree - Fock (SHF) method, where this model has been proven very successful for microscopic description of many nuclear properties near the stable line, such as the nuclear ground-state, collective motion, fission barrier, giant resonance, and heavy-ion collision. With a few adjusting parameters in effective interactions, one can quantitatively reproduce experiment data of nuclei near the stable line by the SHF model [3 - 5].

Nuclear structure investigations of some isotopes had been conducted by some researchers. The nuclear structure of the $\mathrm{Be}, \mathrm{Cr}$, and $\mathrm{Cu}$ isotopes have been investigated by Tel et al. using SHF method [6]. Radii and Density of ${ }^{7-19} \mathrm{~B}$ Isotopes have been also calculated by Tel et al. by using effective Skyrme force [7]. SHF method has been used by Alzubadi et al. to study the microscopic approach of nuclear structure for some $\mathrm{Zr}$ isotopes [8]. The aims of this study are to calculate numerically the groundstate energies of $\mathrm{Pb}$ isotopes (especially ${ }^{204-214} \mathrm{~Pb}$ ) by using the SHF method with Skyrme set parameters (especially SLy4, SkM*, $\mathrm{Z}_{\sigma}$, and SIII) and to simulate the local density as well as the local potential for both proton and neutron. The density distribution and nucleus radii are very important information to understand about nuclear structure. It can be used in scattering research to calculate the microscopic cross-section. Such data is needed in nuclear reactor analysis. Another purpose of this study is to investigate the effect of the increase of neutron number in $\mathrm{Pb}$ nucleus.

\section{Theory}

\section{Skyrme - Hartree - Fock}

The most convenient force used in the description of the ground-state properties of nucleus is the phenomenological Skyrme force first proposed by Skyrme [9]. According to this effective interaction, the force of a zero-range, density, and momentumdependent can be approximated as

(C) Y. Yulianto, Z. Su'ud, 2017 


$$
\begin{aligned}
& V_{\text {Skyrme }}=t_{0}\left(1+x_{0} P_{\sigma}\right) \delta(\vec{r}) \\
& +i t_{4} \vec{k}^{\prime} \cdot \delta(\vec{r})\left(\vec{\sigma}_{i}+\vec{\sigma}_{j}\right) \cdot \vec{k}, \\
& +\frac{1}{2} t_{1}\left(1+x_{1} P_{\sigma}\right)\left\{\delta(\vec{r}) \vec{k}^{2}+\vec{k}^{\prime 2} \delta(\vec{r})\right\} \\
& +t_{2}\left(1+x_{2} P_{\sigma}\right) \vec{k}^{\prime} \cdot \delta(\vec{r}) \vec{k} \\
& +\frac{1}{6} t_{3}\left(1+x_{3} P_{\sigma}\right) \delta(\vec{r}) \rho^{\alpha}\left(\frac{\vec{r}_{i}+\vec{r}_{j}}{2}\right) \\
& E_{\text {Skyme }}=4 \pi \int_{0}^{\infty} d r r^{2}\left\{\frac{\hbar^{2}}{2 m} \tau+\frac{1}{2} t_{0}\left(1+\frac{1}{2} x_{0}\right) \rho^{2}-\frac{1}{2} t_{0}\left(\frac{1}{2}+x_{0}\right) \sum_{q} \rho_{q}^{2}+\frac{1}{12} t_{3}\left(1+\frac{1}{2} x_{3}\right) \rho^{\alpha+2}\right. \\
& -\frac{1}{12} t_{3}\left(\frac{1}{2}+x_{3}\right) \rho^{\alpha} \sum_{q} \rho_{q}^{2}+\frac{1}{4}\left[t_{1}\left(1+\frac{1}{2} x_{1}\right)+t_{2}\left(1+\frac{1}{2} x_{2}\right)\right] \rho \tau \\
& -\frac{1}{4}\left[t_{1}\left(x_{1}+\frac{1}{2}\right)-t_{2}\left(x_{2}+\frac{1}{2}\right)\right] \sum_{q} \rho_{q} \tau_{q}-\frac{1}{16}\left[3 t_{1}\left(1+\frac{1}{2} x_{1}\right)-t_{2}\left(1+\frac{1}{2} x_{2}\right)\right] \rho \nabla^{2} \rho \\
& \left.+\frac{1}{16}\left[3 t_{1}\left(1+\frac{1}{2} x_{1}\right)+t_{2}\left(1+\frac{1}{2} x_{2}\right)\right] \sum_{q} \rho_{q} \nabla^{2} \rho_{q}-\frac{1}{2} t_{4}\left[\rho \vec{\nabla} \vec{J}+\sum_{q} \rho_{q} \vec{\nabla} \vec{J}_{q}\right]\right\} \\
& \vec{\nabla} \vec{J}_{q}(\vec{r})=\left(\frac{\partial}{\partial r}+\frac{2}{r}\right) J_{q}(r), \\
& J_{q}(\vec{r})=\sum_{n_{\beta} j_{\beta} l_{\beta}} w_{\beta} \frac{2 j_{\beta}+1}{4 \pi}\left[j_{\beta}\left(j_{\beta}+1\right)\right. \\
& \left.-l_{\beta}\left(l_{\beta}+1\right)-\frac{3}{4}\right] \frac{2}{r}\left(\frac{R_{\beta}}{r}\right)^{2},
\end{aligned}
$$
such as $\rho=\rho_{p}+\rho_{n}, \quad \tau=\tau_{p}+\tau_{n}, \quad$ and $\vec{\nabla} \vec{J}=\vec{\nabla} \vec{J}_{p}+\vec{\nabla} \vec{J}_{n}$. The total energy follows the form of:

$$
E=E_{\text {Skyme }}+E_{\text {Coul }}+E_{\text {Pair }}-E_{\mathrm{CM}},
$$

where $E_{\text {Skyrme }}$ is the Skyrme interaction energy, $E_{\text {Coul }}$ is the Coulomb interaction energy, $E_{\text {Pair }}$ is the nucleon interaction pairing energy, and $E_{C M}$ is the correction for the spurious center-of-mass motion of the mean field. In other hand, the densities in spherical representation are expressed as

$$
\begin{gathered}
\rho_{q}(r)=\sum_{n_{\beta} j_{\beta} l_{\beta}} w_{\beta} \frac{2 j_{\beta}+1}{4 \pi}\left(\frac{R_{\beta}}{r}\right)^{2}, \\
\tau_{q}(r)=\sum_{n_{\beta} j_{\beta} l_{\beta}} w_{\beta} \frac{2 j_{\beta}+1}{4 \pi}\left[\left(\frac{\partial}{\partial r} \frac{R_{\beta}}{r}\right)^{2}+\frac{l_{\beta} l_{\beta}+1}{r^{2}}\left(\frac{R_{\beta}}{r}\right)^{2}\right],
\end{gathered}
$$

where $\beta$ represents the state, $R_{\beta}$ is the radial wave function, $j_{\beta}$ is the angular momentum, $l_{\beta}$ is the orbital angular momentum $[3,10]$.

In this study, the selected Skyrme force parameters are SLy4 [12], SkM* [13], $Z_{\sigma}$ [4], and SIII [14]. These Skyrme set parameters are widely used in the calculation of the ground-state properties of some nuclei using Hartree - Fock method [7, 11, 15, 16]. The $\mathrm{SkM}^{*}$ force parameters are based on fits of the fission barriers of heavy deformed nuclei and the correction of saturation properties in infinite iso-scalar nuclear matter [13]. The SLy4 forces are described for neutron stars, supernovae, and the neutron-rich nuclei [12]. The SIII is obtained by the adjustment of Skyrme interaction parameters through the binding energy and charge radii fittings of some semi-magic nuclei [14]. The $Z_{\sigma}$ is obtained by the adjustment of Skyrme interaction parameters 
using the mean of the least-squares fitting technique, which optimizes the force parameters such that the Hartree - Fock calculations reproduce the experi- mentally determined nuclear ground-state properties, e.g. binding energy, radii, and surface width [4].

Table 1. The SLy4 [12], SkM* [13], Z $\mathbf{Z}_{\sigma}$ [4], and SIII [14] set parameters for Skyrme interaction

\begin{tabular}{|c|c|c|c|c|}
\hline Parameter & SLy4 & SkM $^{*}$ & $Z_{\sigma}$ & SIII \\
\hline$t_{0}$ & -2488 & -2645 & -1983.76 & 1128.75 \\
\hline$t_{1}$ & 486.82 & 410 & 362.252 & 395 \\
\hline$t_{2}$ & -546.3 & -135 & -104.27 & -95 \\
\hline$t_{3}$ & 13777 & 15595 & 11861.4 & 14000 \\
\hline$x_{0}$ & 0.834 & 0.09 & 1.1717 & 0.45 \\
\hline$x_{1}$ & -0.344 & 0 & 0 & 0 \\
\hline$x_{2}$ & -1 & 0 & 0 & 0 \\
\hline$x_{3}$ & 1.354 & 0 & 1.762 & 1 \\
\hline$t_{4}$ & 123 & 130 & 123.69 & 120 \\
\hline$\alpha$ & 0.167 & 0.167 & 0.25 & 1 \\
\hline
\end{tabular}

Hartree - Fock Method

The single-particle Hartree - Fock equation for the radial wave function $R_{\beta}$ can be expressed as [10]:

$$
h_{q} R_{\beta}=\epsilon_{\beta} R_{\beta}
$$

with the mean-field Hamiltonian

$$
h_{q}=\frac{\partial}{\partial r} B_{q} \frac{\partial}{\partial r}+U_{q}+U_{l s, q} \vec{l} \cdot \vec{\sigma}
$$

where

$$
\begin{aligned}
B_{q}= & \frac{\hbar^{2}}{2 m_{q}}+\frac{1}{8}\left[t_{1}\left(1+\frac{1}{2} x_{1}\right)+t_{2}\left(1+\frac{1}{2} x_{2}\right)\right] \rho \\
& -\frac{1}{8}\left[t_{1}\left(x_{1}+\frac{1}{2}\right)-t_{2}\left(x_{2}+\frac{1}{2}\right)\right] \rho_{q}
\end{aligned}
$$

$$
\begin{gathered}
U_{q}=t_{0}\left(1+\frac{1}{2} x_{0}\right) \rho-t_{0}\left(x_{0}+\frac{1}{2}\right) \rho_{q}+\frac{1}{12} t_{3} \rho^{\alpha}\left[2+\alpha\left(1+\frac{1}{2} x_{3}\right) \rho\right. \\
\left.-2\left(x_{3}+\frac{1}{2}\right) \rho_{q}-\alpha\left(x_{3}+\frac{1}{2}\right)\left(\frac{\rho_{p}^{2}+\rho_{n}^{2}}{\rho}\right)\right]+\frac{1}{4}\left[t_{1}\left(1+\frac{1}{2} x_{1}\right)+t_{2}\left(1+\frac{1}{2} x_{2}\right)\right] \tau \\
-\frac{1}{4}\left[t_{1}\left(x_{1}+\frac{1}{2}\right)-t_{2}\left(x_{2}+\frac{1}{2}\right)\right] \tau_{q}-\frac{1}{8}\left[3 t_{1}\left(1+\frac{1}{2} x_{1}\right)-t_{2}\left(1+\frac{1}{2} x_{2}\right)\right] \Delta \rho \\
+\frac{1}{8}\left[3 t_{1}\left(x_{1}+\frac{1}{2}\right)+t_{2}\left(x_{2}+\frac{1}{2}\right)\right] \Delta \rho_{q}-\frac{1}{2} t_{4} \vec{\nabla} \vec{J}+\vec{\nabla}_{q}+U_{\text {Coul }}, \\
U_{l s, q}=\frac{1}{4} t_{4} \rho+\rho_{q}+\frac{1}{8} t_{1}-t_{2} J_{q}-\frac{1}{8} x_{1} t_{1}+x_{2} t_{2} \quad J,
\end{gathered}
$$

The $U_{l s, q}$ is the form factor of the one-body spinorbit potential, $U_{\text {Coul }}$ is the Coulomb potential, and $U_{q}$ is the potential of nucleon. Coulomb interaction is well-known part of the nucleus Hamiltonian. The Coulomb energy density can be expressed as $[3,17]$

$$
\begin{gathered}
\varepsilon_{\text {Coul }} \vec{r}=\frac{e^{2}}{2} \int \frac{\rho_{p} \vec{r}^{\prime} \rho_{p} \vec{r}}{\left|\vec{r}-\vec{r}^{\prime}\right|} d^{3} r^{\prime} \\
-\frac{3}{4} e^{2}\left(\frac{3}{\pi}\right)^{1 / 3} \rho_{p}^{4 / 3} \vec{r}^{\prime},
\end{gathered}
$$

where the first term represents the direct Coulomb and the second term represents the exchange Coulomb. Because of consuming too much time to evaluate the exchange part exactly (and also it gives small contribution), Coulomb-exchange part is treated in the so-called Slater approximation. The contribution of pairing energy to the total energy can be calculated as

$$
E_{\text {pair }}=-\sum_{q} G_{q}\left[\sum_{\beta \in q} \sqrt{w_{\beta} 1-w_{\beta}}\right]^{2},
$$

where the pairing matrix elements $G_{q}$ are 
constant for each type of nucleon $\left(G_{p r}=\frac{22 \mathrm{MeV}}{A}\right.$ and $G_{n e}=\frac{29 \mathrm{MeV}}{A}$, where $\mathrm{A}$ is the total nucleon number of a nucleus) and $w_{\beta}$ is the pairing weights of the proton and neutron, which can be calculated by using

$$
w_{\beta}=\frac{1}{2}\left(1-\frac{\epsilon_{\beta}-\epsilon_{F, q}}{\sqrt{\epsilon_{\beta}-\epsilon_{F, q}^{2}+\Delta_{q}^{2}}}\right),
$$

where

$$
\frac{\Delta_{q}}{G_{q}}=\sum_{\beta \in q} \sqrt{w_{\beta} 1-w_{\beta}} .
$$

The $\Delta_{q}$ is the pairing gap, $\epsilon_{\beta}$ is the singleparticle energy of state $\beta$, and $\epsilon_{F, q}$ is the Fermi energy. The detail explanation of pairing energy can be found in the following references $[10,16]$. The root-mean-square (rms) radii of charge, mass, neutron and proton can be defined as the following formula $[6,18]$

$$
r_{q}=\left\langle r_{q}^{2}\right\rangle^{\frac{1}{2}}=\left[\int \vec{r}^{2} \rho_{q} \vec{r} d^{3} \vec{r}\right]^{\frac{1}{2}}\left[\int \rho_{q} \vec{r} d^{3} \vec{r}\right]^{-\frac{1}{2}}
$$

and the neutron skin thickness can be defined as the difference between the neutron rms radius and the proton rms radius as $[6,19]$

$$
t=r_{n}-r_{p}
$$

\section{Result and Discussion}

\section{Total Energy and Radii Calculations}

Calculation results of total energy for each nucleus used in this study are presented in Table 2 . It can be seen in Table 2 that the total energies calculated by $Z_{\sigma}$ are in very good agreement with the related experiment results where the discrepancies are in the range of $0.008-0.243 \%$, followed by $\mathrm{SkM}^{*}$ results as the second best fit with 0.618 $0.934 \%$ of discrepancies. Next, SLy4 results, as the third best fit, have the discrepancies of about 1.127 $1.526 \%$, followed by SIII results, as the fourth best fit, with $1.261-1.541 \%$ of discrepancies.

In this study, the charge, mass, proton, and neutron radii for each nucleus have been also calculated. From Table 2 to Table 7, it can be seen that all calculation results are in good agreement with the experiment results as well as Tel et al. results. For charge radius calculations (Table 3), it can be seen that $\mathrm{SkM}^{*}$ results are in very good agreement with the experiment results, followed by the results of SLy4, SIII, and $Z_{\sigma}$, respectively. For proton radius of ${ }^{208} \mathrm{~Pb}$ (Table 5), the SIII result is the best fit to the experiment result, followed by the results of SLy4, SkM*, and $\mathrm{Z}_{\sigma}$, respectively. For neutron radius of ${ }^{208} \mathrm{~Pb}$ (Table 6), the SLy4 result is the best fit to the experiment result, followed by the results of $\mathrm{SkM}^{*}$, SIII, and $\mathrm{Z}_{\sigma}$, respectively.

In the neutron skin thickness calculation for ${ }^{208} \mathrm{~Pb}$ (Table 7), by using experiment result given in Tables 5 and 6 , it can be obtained theoretically that the neutron skin thickness of ${ }^{208} \mathrm{~Pb}$ is $0.06 \mathrm{fm}$. By using this calculation result, it can be seen that the $Z_{\sigma}$ result is the best fit, followed by the results of SIII, SLy4, and $\mathrm{SkM}^{*}$, respectively. It can be indicated that the $Z_{\sigma}$ is good enough to explain surface phenomena. In other hand, the $Z_{\sigma}$ results are in contradiction with the results of SIII, SLy4, and SkM* set parameters. The results of SIII, SLy4, and SkM* are similar to each other but the results of $Z_{\sigma}$ are twice smaller than the results of SIII and three times smaller than those of SLy4 and SkM*. These contradictions need further investigation. From those results, it can be seen that, in $\mathrm{Pb}$ nucleus, the total energy, mass radius, neutron radius, and neutron skin thickness increase with the increase of neutron number. In contrast, the increase

\begin{tabular}{|c|c|c|c|c|c|}
\hline \multirow{2}{*}{ Nucleus } & \multirow{2}{*}{$\begin{array}{l}\text { Exp. } \\
{[20]}\end{array}$} & \multicolumn{4}{|c|}{ This study } \\
\hline & & SLy4 & $\mathrm{SkM}^{*}$ & $Z_{\sigma}$ & SIII \\
\hline${ }^{204} \mathrm{~Pb}$ & -1607.506 & -1586.060 & -1592.495 & -1605.806 & $\begin{array}{l}-1585.495 \\
\end{array}$ \\
\hline${ }^{205} \mathrm{~Pb}$ & -1614.238 & -1594.414 & -1601.143 & -1614.083 & -1593.442 \\
\hline${ }^{206} \mathrm{~Pb}$ & -1622.324 & -1602.639 & -1609.630 & -1622.179 & -1601.122 \\
\hline${ }^{207} \mathrm{~Pb}$ & -1629.062 & -1610.687 & -1617.891 & -1630.062 & -1608.520 \\
\hline${ }^{208} \mathrm{~Pb}$ & -1636.430 & -1617.492 & -1624.896 & -1636.816 & -1614.805 \\
\hline${ }^{209} \mathrm{~Pb}$ & -1640.367 & -1621.865 & -1630.219 & -1641.434 & -1619.592 \\
\hline${ }^{210} \mathrm{~Pb}$ & -1645.552 & -1625.307 & -1634.713 & -1645.233 & -1623.488 \\
\hline${ }^{211} \mathrm{~Pb}$ & -1649.387 & -1628.557 & -1639.007 & -1648.830 & -1627.145 \\
\hline${ }^{212} \mathrm{~Pb}$ & -1654.514 & -1631.721 & -1643.186 & -1652.358 & -1630.699 \\
\hline${ }^{213} \mathrm{~Pb}$ & -1658.240 & -1634.846 & -1647.282 & -1655.817 & -1634.196 \\
\hline${ }^{214} \mathrm{~Pb}$ & -1663.290 & -1637.909 & -1651.319 & -1659.241 & -1637.660 \\
\hline
\end{tabular}
of neutron number has smaller effect to the proton radius compared to that of neutron.

Table 2. Calculation results for the total energy of $\mathrm{Pb}$ isotopes (all units are in $\mathrm{MeV}$ ) 
Table 3. Calculation results for charge radius of $\mathbf{P b}$ isotopes (all units are in $\mathbf{f m}$ )

\begin{tabular}{|c|c|c|c|c|c|c|c|}
\hline \multirow{2}{*}{ Nucleus } & \multicolumn{4}{|c|}{ This study } & \multicolumn{2}{|c|}{ Tel et al. [18] } & \multirow{2}{*}{ Exp. [21] } \\
\hline & SLy4 & SkM* & $\mathrm{Z}_{\sigma}$ & SIII & SIII & SkM* & \\
\hline${ }^{204} \mathrm{~Pb}$ & 5.505 & 5.495 & 5.427 & 5.559 & 5.555 & 5.494 & $5.4803 \pm 0.0014$ \\
\hline${ }^{205} \mathrm{~Pb}$ & 5.509 & 5.500 & 5.432 & 5.564 & - & - & $5.4828 \pm 0.0015$ \\
\hline${ }^{206} \mathrm{~Pb}$ & 5.513 & 5.505 & 5.436 & 5.570 & 5.566 & 5.503 & $5.4902 \pm 0.0014$ \\
\hline${ }^{207} \mathrm{~Pb}$ & 5.517 & 5.509 & 5.440 & 5.575 & - & - & $5.4943 \pm 0.0014$ \\
\hline${ }^{208} \mathrm{~Pb}$ & 5.522 & 5.514 & 5.445 & 5.581 & 5.578 & 5.513 & $5.5012 \pm 0.0013$ \\
\hline${ }^{209} \mathrm{~Pb}$ & 5.529 & 5.520 & 5.451 & 5.588 & - & - & $5.51 \pm 0.0014$ \\
\hline${ }^{210} \mathrm{~Pb}$ & 5.535 & 5.526 & 5.455 & 5.595 & - & - & $5.5208 \pm 0.0016$ \\
\hline${ }^{211} \mathrm{~Pb}$ & 5.541 & 5.531 & 5.460 & 5.603 & - & - & $5.529 \pm 0.0017$ \\
\hline${ }^{212} \mathrm{~Pb}$ & 5.547 & 5.536 & 5.464 & 5.610 & - & - & $5.5396 \pm 0.0019$ \\
\hline${ }^{213} \mathrm{~Pb}$ & 5.552 & 5.541 & 5.469 & 5.617 & - & - & - \\
\hline${ }^{214} \mathrm{~Pb}$ & 5.558 & 5.546 & 5.473 & 5.625 & - & - & $5.5577 \pm 0.0023$ \\
\hline
\end{tabular}

Table 4. Calculation results for mass radius of $\mathbf{P b}$ isotopes (all units are in $\mathbf{f m}$ )

\begin{tabular}{|c|c|c|c|c|c|c|}
\hline \multirow{2}{*}{ Nucleus } & \multicolumn{3}{|c|}{ This study } & \multicolumn{2}{c|}{ Tel et al. [18] } \\
\cline { 2 - 6 } & SLy4 & SkM* & $Z_{\sigma}$ & SIII & SIII & SkM* \\
\hline${ }^{204} \mathrm{~Pb}$ & 5.534 & 5.529 & 5.403 & 5.573 & 5.567 & 5.527 \\
\hline${ }^{205} \mathrm{~Pb}$ & 5.542 & 5.537 & 5.408 & 5.580 & - & - \\
\hline${ }^{206} \mathrm{~Pb}$ & 5.549 & 5.546 & 5.414 & 5.588 & 5.583 & 5.544 \\
\hline${ }^{207} \mathrm{~Pb}$ & 5.557 & 5.554 & 5.419 & 5.597 & - & - \\
\hline${ }^{208} \mathrm{~Pb}$ & 5.565 & 5.563 & 5.425 & 5.605 & 5.603 & 5.562 \\
\hline${ }^{209} \mathrm{~Pb}$ & 5.578 & 5.575 & 5.435 & 5.617 & - & - \\
\hline${ }^{210} \mathrm{~Pb}$ & 5.588 & 5.585 & 5.442 & 5.627 & - & - \\
\hline${ }^{211} \mathrm{~Pb}$ & 5.599 & 5.595 & 5.449 & 5.637 & - & - \\
\hline${ }^{212} \mathrm{~Pb}$ & 5.610 & 5.605 & 5.456 & 5.648 & - & - \\
\hline${ }^{213} \mathrm{~Pb}$ & 5.621 & 5.616 & 5.463 & 5.658 & - & - \\
\hline${ }^{214} \mathrm{~Pb}$ & 5.631 & 5.626 & 5.470 & 5.668 & - & - \\
\hline
\end{tabular}

Table 5. Calculation results for proton radius of $\mathrm{Pb}$ isotopes (all units are in $\mathbf{f m}$ )

\begin{tabular}{|c|c|c|c|c|c|c|c|}
\hline \multirow{2}{*}{ Nucleus } & \multicolumn{4}{|c|}{ This study } & \multicolumn{2}{|c|}{ Tel et al. [18] } & \multirow{2}{*}{$\begin{array}{c}\text { Exp. } \\
{[18,22]}\end{array}$} \\
\hline & SLy4 & SkM* & $\mathrm{Z}_{\sigma}$ & SIII & SIII & SkM* & \\
\hline${ }^{204} \mathrm{~Pb}$ & 5.450 & 5.441 & 5.375 & 5.508 & 5.502 & 5.439 & - \\
\hline${ }^{205} \mathrm{~Pb}$ & 5.454 & 5.446 & 5.380 & 5.514 & - & - & - \\
\hline${ }^{206} \mathrm{~Pb}$ & 5.459 & 5.451 & 5.384 & 5.519 & 5.513 & 5.448 & - \\
\hline${ }^{207} \mathrm{~Pb}$ & 5.463 & 5.455 & 5.388 & 5.524 & - & - & - \\
\hline${ }^{208} \mathrm{~Pb}$ & 5.468 & 5.461 & 5.393 & 5.531 & 5.528 & 5.460 & 5.5 \\
\hline${ }^{209} \mathrm{~Pb}$ & 5.476 & 5.467 & 5.400 & 5.538 & - & - & - \\
\hline${ }^{210} \mathrm{~Pb}$ & 5.482 & 5.473 & 5.404 & 5.545 & - & - & - \\
\hline${ }^{211} \mathrm{~Pb}$ & 5.488 & 5.478 & 5.410 & 5.552 & - & - & - \\
\hline${ }^{212} \mathrm{~Pb}$ & 5.494 & 5.484 & 5.414 & 5.559 & - & - & - \\
\hline${ }^{213} \mathrm{~Pb}$ & 5.500 & 5.490 & 5.420 & 5.566 & - & - & - \\
\hline${ }^{214} \mathrm{~Pb}$ & 5.507 & 5.495 & 5.425 & 5.573 & - & - & - \\
\hline
\end{tabular}

Table 6. Calculation results for neutron radius of $\mathbf{P b}$ isotopes (all units are in $\mathbf{f m}$ )

\begin{tabular}{|c|c|c|c|c|c|c|c|}
\hline \multirow{2}{*}{ Nucleus } & \multicolumn{4}{|c|}{ This study } & \multicolumn{2}{|c|}{ Tel et al. [18] } & \multirow{2}{*}{$\begin{array}{c}\text { Exp. } \\
{[18,22]}\end{array}$} \\
\hline & SLy4 & SkM* & $Z_{\sigma}$ & SIII & SIII & SkM* & \\
\hline${ }^{204} \mathrm{~Pb}$ & 5.589 & 5.587 & 5.421 & 5.615 & 5.61 & 5.585 & - \\
\hline${ }^{205} \mathrm{~Pb}$ & 5.599 & 5.597 & 5.427 & 5.625 & - & - & - \\
\hline${ }^{206} \mathrm{~Pb}$ & 5.608 & 5.608 & 5.434 & 5.634 & 5.628 & 5.606 & - \\
\hline${ }^{207} \mathrm{~Pb}$ & 5.618 & 5.618 & 5.439 & 5.643 & - & - & - \\
\hline${ }^{208} \mathrm{~Pb}$ & 5.627 & 5.628 & 5.446 & 5.654 & 5.65 & 5.627 & 5.56 \\
\hline${ }^{209} \mathrm{~Pb}$ & 5.642 & 5.643 & 5.457 & 5.667 & - & - & - \\
\hline${ }^{210} \mathrm{~Pb}$ & 5.656 & 5.656 & 5.466 & 5.679 & - & - & - \\
\hline${ }^{211} \mathrm{~Pb}$ & 5.669 & 5.668 & 5.474 & 5.691 & - & - & - \\
\hline${ }^{212} \mathrm{~Pb}$ & 5.682 & 5.681 & 5.482 & 5.702 & - & - & - \\
\hline${ }^{213} \mathrm{~Pb}$ & 5.695 & 5.693 & 5.490 & 5.714 & - & - & - \\
\hline${ }^{214} \mathrm{~Pb}$ & 5.707 & 5.705 & 5.498 & 5.725 & - & - & - \\
\hline
\end{tabular}


Table 7. Calculation results for neutron skin thickness of $\mathbf{P b}$ isotopes (all units are in fm)

\begin{tabular}{|c|c|c|c|c|c|c|}
\hline \multirow{2}{*}{ Nucleus } & \multicolumn{3}{|c|}{ This study } & \multicolumn{2}{c|}{ Tel et al. [18] } \\
\cline { 2 - 7 } & SLy4 & SkM* & $Z_{\sigma}$ & SIII & SIII & SkM* \\
\hline${ }^{204} \mathrm{~Pb}$ & 0.139 & 0.146 & 0.046 & 0.107 & 0.108 & 0.146 \\
\hline${ }^{205} \mathrm{~Pb}$ & 0.145 & 0.151 & 0.047 & 0.111 & - & - \\
\hline${ }^{206} \mathrm{~Pb}$ & 0.149 & 0.157 & 0.050 & 0.115 & 0.115 & 0.158 \\
\hline${ }^{207} \mathrm{~Pb}$ & 0.155 & 0.163 & 0.051 & 0.119 & - & - \\
\hline${ }^{208} \mathrm{~Pb}$ & 0.159 & 0.167 & 0.053 & 0.123 & 0.122 & 0.167 \\
\hline${ }^{209} \mathrm{~Pb}$ & 0.166 & 0.176 & 0.057 & 0.129 & - & - \\
\hline${ }^{210} \mathrm{~Pb}$ & 0.174 & 0.183 & 0.062 & 0.134 & - & - \\
\hline${ }^{211} \mathrm{~Pb}$ & 0.181 & 0.190 & 0.064 & 0.139 & - & - \\
\hline${ }^{212} \mathrm{~Pb}$ & 0.188 & 0.197 & 0.068 & 0.143 & - & - \\
\hline${ }^{213} \mathrm{~Pb}$ & 0.195 & 0.203 & 0.070 & 0.148 & - & - \\
\hline${ }^{214} \mathrm{~Pb}$ & 0.200 & 0.210 & 0.073 & 0.152 & - & - \\
\hline
\end{tabular}

\subsection{The Density and the Potential of Nucleons}

In this paper, it is also investigated the effect of the increase of neutron number in $\mathrm{Pb}$ nucleus. First, it is investigated the density and the potential of nucleons calculated by SLy4, SkM*, $\mathrm{Z}_{\sigma}$, and SIII set parameters.

In Figs. 1-5, for proton density (part $a$ ), at $\mathrm{r}<0.5 \mathrm{fm}$, the SLy4 obtained the largest results and the SIII obtained the smallest results. In radius 2 - $6 \mathrm{fm}$, the $Z_{\sigma}$ obtained the largest results and the SIII obtained the smallest results. From neutron

Proton density, $\mathrm{fm}^{-3}$

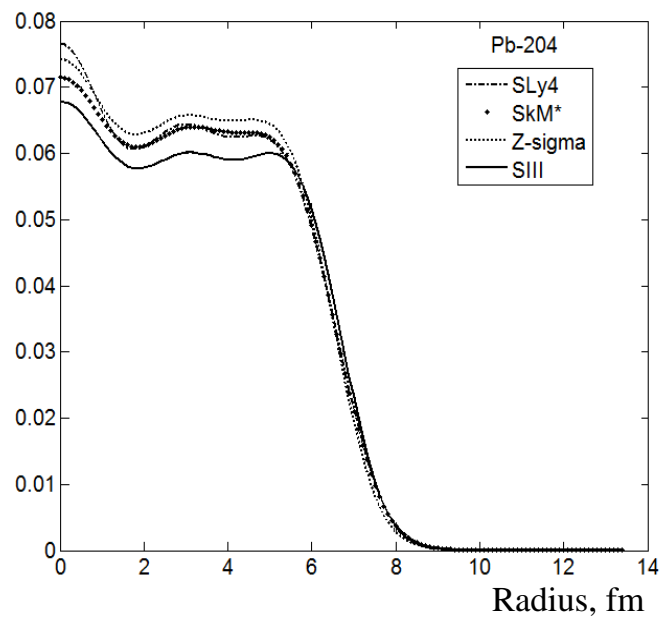

$a$ density (part $b$ ), at $\mathrm{r}<0.5 \mathrm{fm}$, the $\mathrm{Z}_{\sigma}$ obtained the largest results and the SLy4 obtained the smallest results. In radius $2-6 \mathrm{fm}$, for both proton and neutron, the $Z_{\sigma}$ obtained the largest results and the SIII obtained the smallest results. The results of SLy4 and SkM* are similar in this area. Proton density has maximum value at $r<0.5 \mathrm{fm}$ and neutron density has maximum value in radius $2-5 \mathrm{fm}$. In radius $6-8 \mathrm{fm}$, the densities of proton and neutron decreased drastically and it approached to zero smoothly at $\mathrm{r}>8 \mathrm{fm}$.

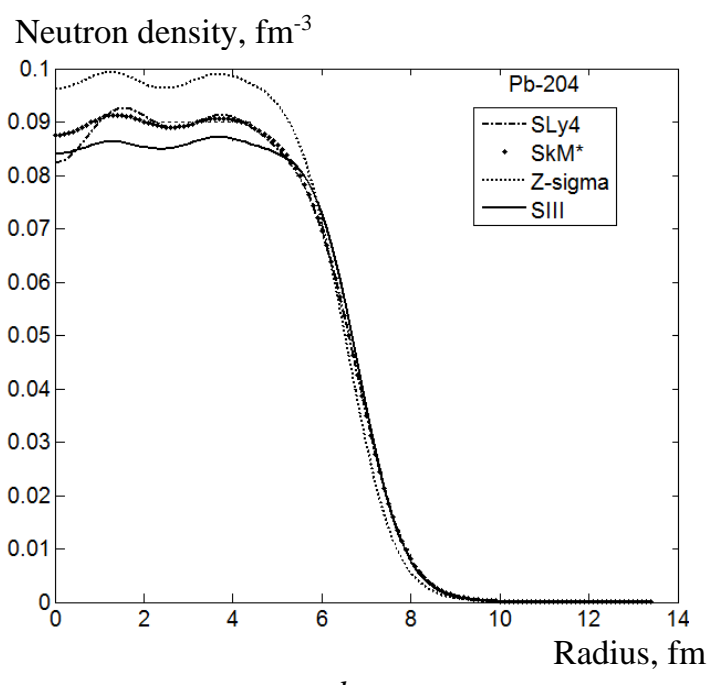

$b$

Fig. 1. Local densities of proton $(a)$ and neutron $(b)$ of ${ }^{204} \mathrm{~Pb}$.

In this study, it has been taken the results of $\mathrm{SkM}^{*}$ set parameters to investigate the effect of the increase of neutron number in $\mathrm{Pb}$ nucleus. In Fig. 6, $a$, in region $0-6 \mathrm{fm}$, the proton density of ${ }^{178} \mathrm{~Pb}$ is the largest and ${ }^{220} \mathrm{~Pb}$ is the smallest. The proton density widths of ${ }^{178} \mathrm{~Pb},{ }^{208} \mathrm{~Pb}$, and ${ }^{220} \mathrm{~Pb}$ are almost similar. In Fig. 6, $b$, in region $2-4 \mathrm{fm}$, the neutron density of ${ }^{178} \mathrm{~Pb}$ is the smallest and ${ }^{220} \mathrm{~Pb}$ is the largest. The neutron density width of ${ }^{178} \mathrm{~Pb}$ is the smallest and ${ }^{220} \mathrm{~Pb}$ is the biggest. It is indicated that the increase of neutron number causes the decrease of proton density and has minimum effect to the proton density width. In contrast, the increase of neutron number causes substantial effect for neutron density, where the increase of neutron number causes the increase of neutron density and its width.

In Fig. 7, $a$, in region $0-4 \mathrm{fm}$, the proton potential depth of ${ }^{178} \mathrm{~Pb}$ is the shallowest and ${ }^{220} \mathrm{~Pb}$ is the deepest. The proton potential width of ${ }^{178} \mathrm{~Pb}$ is the smallest and ${ }^{220} \mathrm{~Pb}$ is the largest. In Fig. $7, b$, in region $2-4 \mathrm{fm}$, the neutron potential of ${ }^{178} \mathrm{~Pb}$ is the deepest and ${ }^{220} \mathrm{~Pb}$ is the shallowest. The neutron potential widths of ${ }^{178} \mathrm{~Pb},{ }^{208} \mathrm{~Pb}$, and ${ }^{220} \mathrm{~Pb}$ are almost similar to each other. It can be indicated that the 
depth and width of proton potentials increase with the increase of neutron number. In other hand, the increase of neutron number causes the decrease of neutron potential depth and has minimum effect to the neutron potential width.

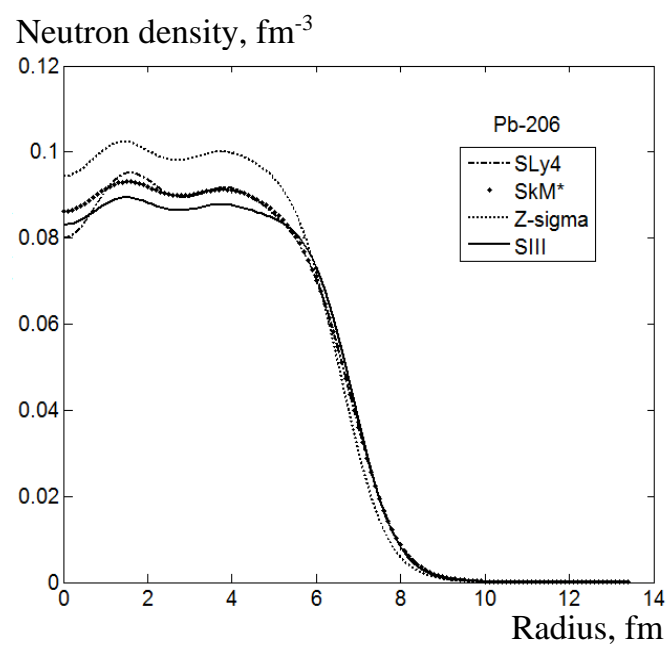

$b$

Fig. 2. Local densities of proton $(a)$ and neutron $(b)$ of ${ }^{206} \mathrm{~Pb}$.

Proton density, $\mathrm{fm}^{-3}$

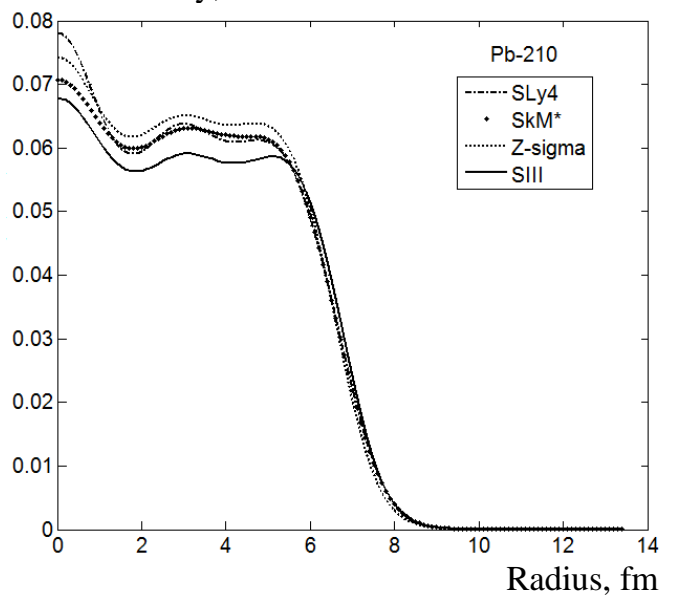

$a$
Neutron density, $\mathrm{fm}^{-3}$

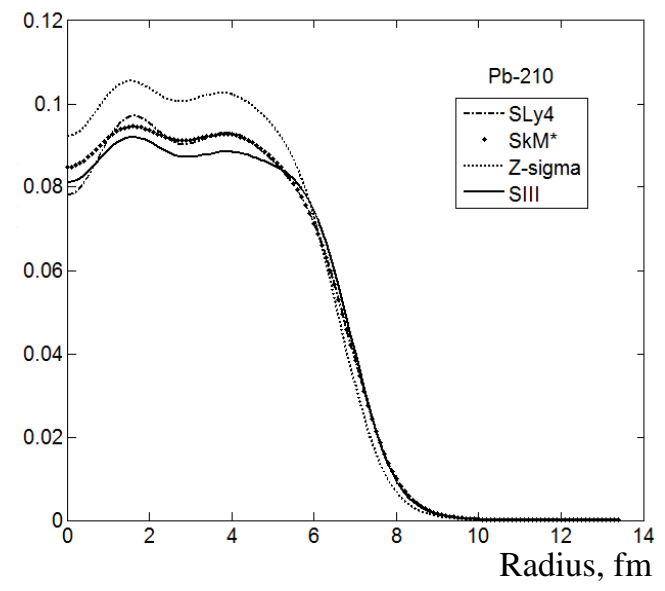

$b$

Fig. 3. Local densities of proton $(a)$ and neutron $(b)$ of ${ }^{210} \mathrm{~Pb}$.

Proton density, $\mathrm{fm}^{-3}$

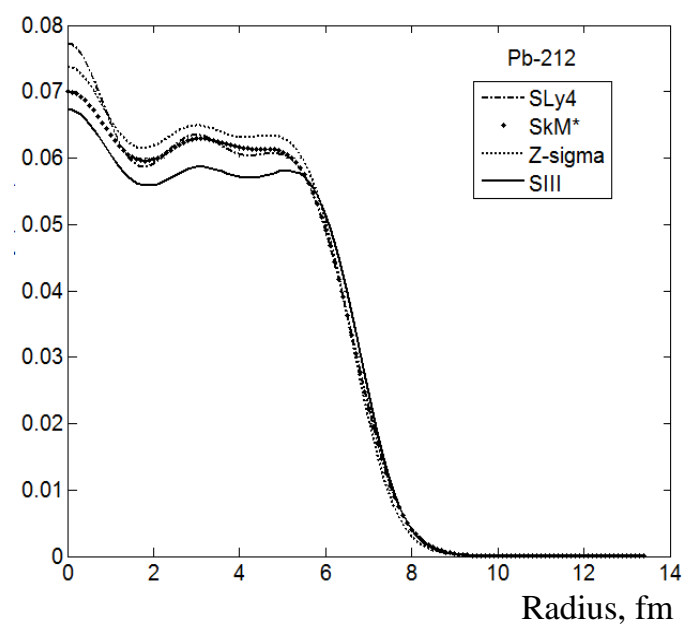

Neutron density, $\mathrm{fm}^{-3}$

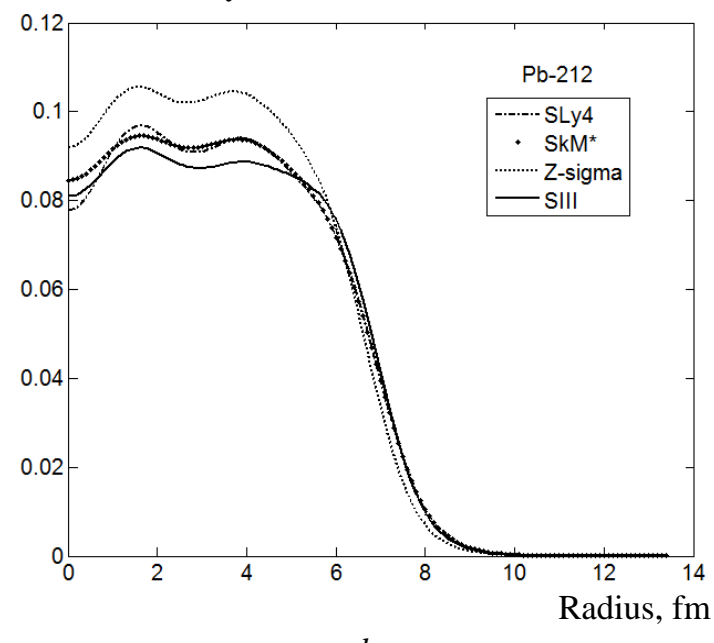

Fig. 4. Local densities of proton $(a)$ and neutron $(b)$ of ${ }^{212} \mathrm{~Pb}$. 
Proton density, $\mathrm{fm}^{-3}$

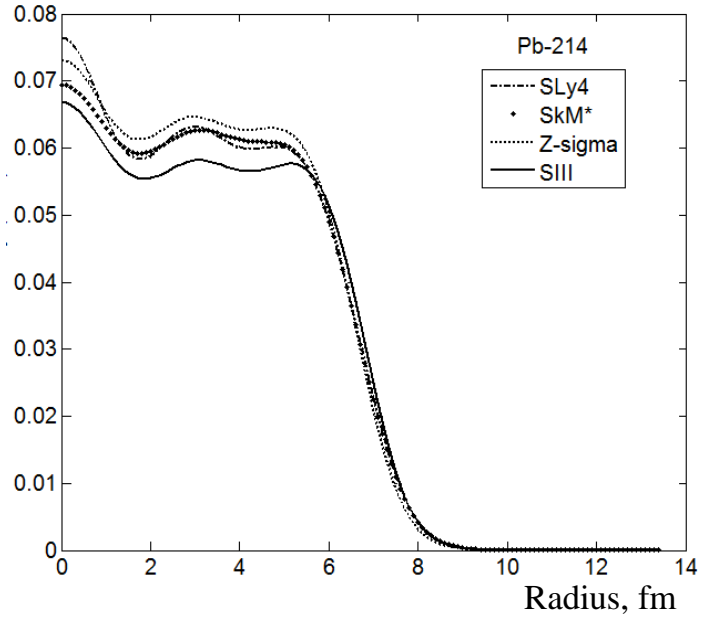

$a$
Neutron density, $\mathrm{fm}^{-3}$

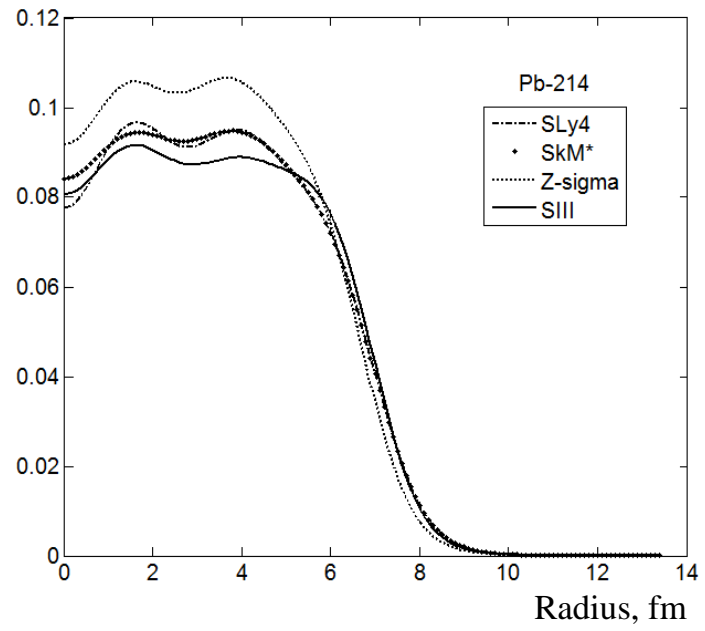

$b$

Fig. 5. Local densities of proton $(a)$ and neutron $(b)$ of ${ }^{214} \mathrm{~Pb}$.

Proton density, $\mathrm{fm}^{-3}$

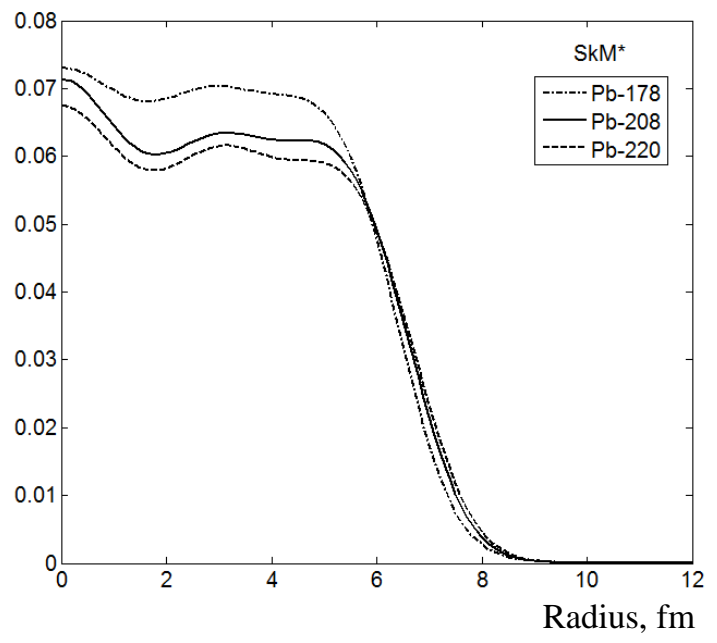

$a$
Neutron density, $\mathrm{fm}^{-3}$

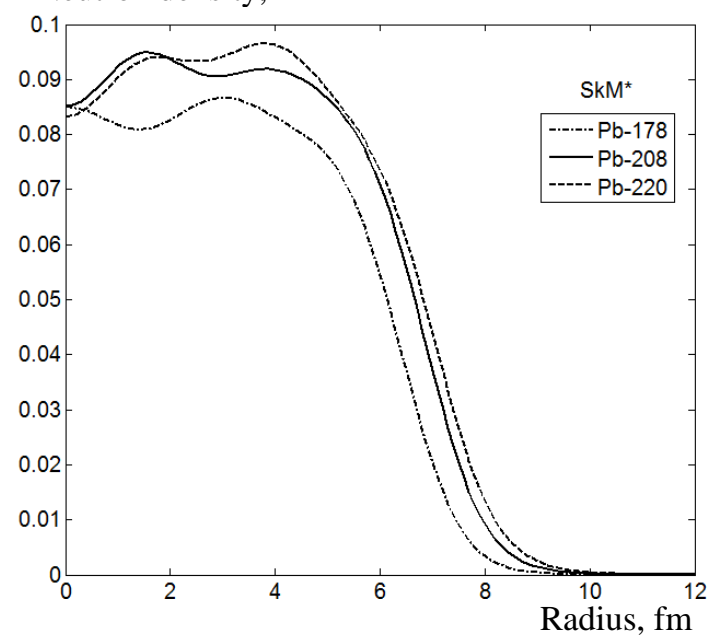

$b$

Fig. 6. Local densities of proton $(a)$ and neutron $(b)$ with $\mathrm{SkM}^{*}$ set parameters.

Proton potential, $\mathrm{MeV}$

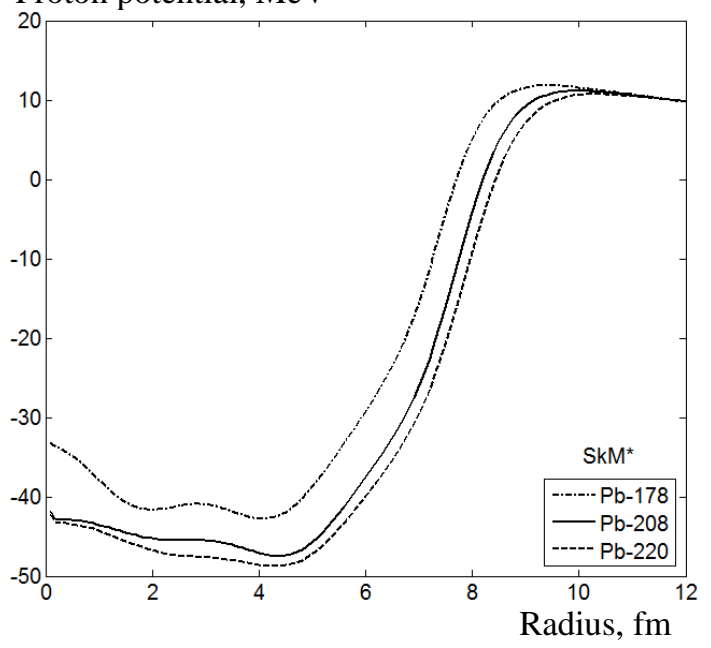

$a$

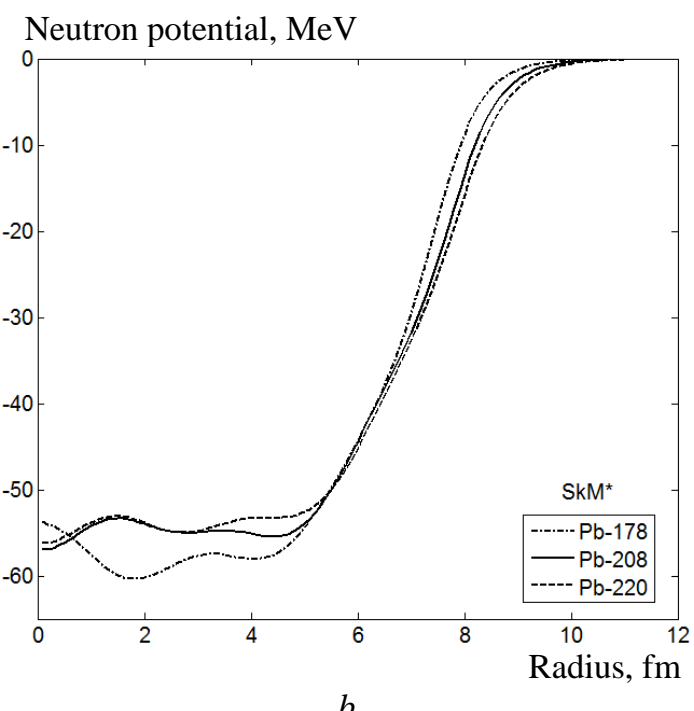

$b$

Fig. 7. Local potentials of proton $(a)$ and neutron $(b)$ with $\mathrm{SkM}^{*}$ set parameters. 


\section{Conclusion}

It has been performed an investigation of nuclear ground-state properties of spherical nuclei, such as the total energy, nucleon local density, and nucleon local potential of $\mathrm{Pb}$ isotopes (especially ${ }^{204-214} \mathrm{~Pb}$ ) by using SHF method, with Skyrme set parameters, especially SLy4, SkM*, $\mathrm{Z}_{\sigma}$, and SIII set parameters. All used parameters are in good agreement with the results of the related experiments and the other researchers. From this study, it is also obtained that, in $\mathrm{Pb}$ nucleus, the total energy, mass radius, neutron radius, neutron skin thickness, neutron density, neutron density width, proton potential depth, and proton potential width increase accordingly with the increase of neutron number. In other hand, proton density and neutron potential decrease accordingly with the increase of neutron number. The increase of neutron number has minimum effect to the widths of proton density and neutron potential.

The authors are grateful to Prof. P. G. Reinhard (Germany) for discussion and guide in using the HAFOMN code.

\section{REFERENCES}

1. Z. Su'ud et al. Desain Study of Pb-Bi Cooled Fast Reactors with Natural Uranium as Fuel Cycle Input Using Special Shuffling Strategy in Radial Direction. Advanced Materials Research 772 (2013) 530.

2. G.L. Khorasanov, A.I. Blokhin. Some Advantages in Using Lead-208 as Coolant for Fast Reactors and Accelerator Driven Systems. In: Application of Stable Lead Isotope Pb-208 in Nuclear Power Engineering and its Acquisition Techniques. Ed. by G.L. Khorasanov (New York: Nova Science Pub Inc., 2013) p. 1.

3. D. Vautherin, D.M. Brink. Hartree - Fock calculation with Skyrme's interaction. I. Spherical nuclei. Phys. Rev. C 5 (1972) 626.

4. J. Friedrich, P.-G. Reinhard. Skyrme-force parametrization: Least-squares fit to nuclear ground-state properties. Phys. Rev. C 33 (1986) 335.

5. J. Dobaczewski et al. Nuclear shell structure at particle drip lines. Phys. Rev. Lett. 72 (1994) 981.

6. E. Tel et al. Investigation of the nuclear structure of the $\mathrm{Be}, \mathrm{Cr}$, and $\mathrm{Cu}$ isotopes. Annals of Nuclear Energy 36 (2009) 1333.

7. E. Tel et al. Calculation of Radii and Density of ${ }^{7-19} \mathrm{~B}$ Isotopes Using Effective Skyrme Force. Commun. Theor. Phys. 49 (2008) 696.

8. A.A. Alzubadi, Z.A. Dakhil, S.T. Aluboodi. Microscopic study of nuclear structure for some $\mathrm{Zr}$ isotopes Using Skyrme-Hartree-Fock Method. Journal of Nuclear and Particle Physics 4(6) (2014) 155.

9. T.H.R. Skyrme. The effective nuclear potential. Nucl. Phys. 9 (1959) 615.

10. P.-G. Reinhard. The Skyrme - Hartree - Fock model of the nuclear ground state. In: Computational Nuclear Physics. I. Nuclear Structure. Ed. by K. Langanke, J. Maruhn, S.E. Koonin (Berlin: SpringerVerlag, 1991) p. 28.

11. H. Aytekin, D. Demirbag. Investigation of the nuclear properties of ${ }^{181} \mathrm{Ta}$ and ${ }^{182,183,184,186 \mathrm{~W}}$ structural materials. Indian Journal Phys. 87 (2013) 487.

12. E. Chabanat et al. A Skyrme parametrization from subnuclear to neutron star densities. Nucl. Phys. A 627 (1997) 710.

13. J. Bartel et al. Towards a better parametrization of Skyrme-like effective forces: A critical study of the SkM force. Nucl. Phys. A 386 (1982) 79.

14. M. Beiner et al. Nuclear ground-state properties and self-consistent calculations with the Skyrme interaction (I). Spherical description. Nucl. Phys. A 238 (1975) 29.

15. J. Erler, P. Klupfel, P.-G. Reinhard. Self-consistent nuclear mean-field models: Example Skyrme Hartree - Fock. J. Phys. G: Nucl. Phys. 38 (2011) 033101.

16. H. Aytekin, E. Tel, R. Baldik. Investigation of the Ground State Features of Some Excotic Nuclei by Using Effective Skyrme Interaction. Turk J. Phys. 32 (2008) 181.

17. H. Gu et al. Slater approximation for Coulomb exchange effects in nuclear covariant density functional theory. Phys. Rev. C 87 (2013) 041301.

18. E. Tel, A. Aydin. Investigation of Lead Target Nuclei Used on Accelerator-Driven Systems for Tritium Production. J. Fusion Energy 31 (2012) 73.

19. W.D. Myers, W.J. Swiatecky. Average Nuclear Properties. Ann. Phys. 55 (1969) 395.

20. M. Wang et al. The AME2012 atomic mass evolution (II). Tables, graphs and references. Chinese Physics C 36 (2012) 1603.

21. I. Angeli, K.P. Marinova. Table of experimental nuclear ground state charge radii: An update. Atomic Data and Nuclear Data Tables 99 (2013) 69.

22. G.-Q. Li. A systematic study of nuclear properties with Skyrme forces. J. Phys. G: Nucl. Part. Phys. 17 (1991) 1. 


\section{Ю. Юліанто*, 3. Сууд}

Фізичний факультет, Бандунгський технологічний інститут, Бандунг, Індонезія

*Відповідальний автор: уacyulianto@gmail.com

\section{ЕНЕРГІЯ ЗВ'ЯЗКУ ЯДЕР ТА РОЗПОДІЛ ГУСТИНИ В ІЗОТОПАХ СВИНЦЮ В МЕТОДІ СКІРМА - ХАРТРІ - ФОКА}

У цьому дослідженні вивчено основні властивості сферичних ядер, такі як сумарна енергія, локальна густина нуклонів та локальний нуклонний потенціал ізотопів свинцю (особливо ${ }^{204-214} \mathrm{~Pb}$ ) за допомогою методу

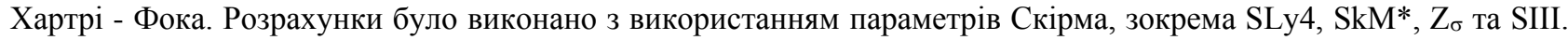
Результати розрахунків порівнюються з експериментальними результатами та результатами розрахунків інших дослідників. Усі використані параметри добре узгоджуються з результатами відповідних експериментів та інших розрахунків. 3 дослідження випливає, що в ізотопах свинцю сумарна енергія, масовий радіус, нейтронний радіус, товщина нейтронної шкіри, нейтронна густина, ширина нейтронного розподілу, глибина та ширина протонного потенціалу зростають із збільшенням числа нейтронів. 3 іншого боку, густина протонів та нейтронний потенціал зменшуються із збільшенням числа нейтронів. Збільшення кількості нейтронів мінімально впливає на ширину густини протонів та нейтронний потенціал.

Ключові слова: Хартрі - Фок, локальна густина, енергія зв'язку ядер, ізотопи свинцю, взаємодія Скірма.

\section{Ю. Юлианто*, 3. Сууд}

Физический факультет, Бандунгский технологический институт, Бандунг, Индонезия

*Ответственный автор: уacyulianto@gmail.com

\section{ЭНЕРГИЯ СВЯЗИ ЯДЕР И РАСПРЕДЕЛЕНИЕ ПЛОТНОСТИ В ИЗОТОПАХ СВИНЦА В МЕТОДЕ СКИРМА - ХАРТРИ - ФОКА}

В этом исследовании изучены основные свойства сферических ядер, такие как суммарная энергия, локальная плотность нуклонов и локальный нуклонный потенциал изотопов свинца (особенно ${ }^{204-214} \mathrm{~Pb}$ ) $\mathrm{c}$ помощью метода Хартри - Фока. Расчеты были выполнены с использованием параметров Скирма, в частности SLy4, SkM*, Z $\sigma$ и SIII. Результаты расчетов сравниваются с экспериментальными результатами и результатами других расчетов. Все использованные параметры хорошо согласуются с результатами соответствующих экспериментов и других расчетов. Из исследования вытекает, что в изотопах свинца суммарная энергия, массовый радиус, нейтронный радиус, толщина нейтронной кожи, нейтронная плотность, ширина нейтронного распределения, глубина и ширина протонного потенциала увеличиваются при увеличении числа нейтронов. С другой стороны, плотность протонов и нейтронный потенциал уменьшаются при увеличении числа нейтронов. Увеличение числа нейтронов минимально влияет на ширину плотности протонов и нейтронный потенциал.

Ключевые слова: Хартри - Фок, локальная плотность, энергия связи ядер, изотопы свинца, взаимодействие Скирма.

Надійшла 28.03.2017

Received 28.03.2017 